\title{
ЭКОНОМИЧЕСКАЯ ЭФФЕКТИВНОСТЬ И ЕЁ СВЯЗЬ С КЛАССИЧЕСКИМИ ТЕОРИЯМИ СТОИМОСТИ И ПОЛЕЗНОСТИ
}

\author{
(C) 2019 Гуськова Марина Федоровна \\ доктор экономических наук, профессор кафедры “Менеджмент качества” \\ Российский университет транспорта (РУТ (МИИТ)) \\ 127994, г. Москва, ул. Образцова, д. 9 , стр. 9
}

В статье анализируются формы одновременного и последовательного проявления классических теорий стоимости и полезности в рыночной экономике. Обосновываются практические подходы к оценке стоимости и полезности в отдельности и их взаимозависимости и взаимосвязи в процессе производства благ.

Ключевые слова: полезность, стоимость, ценность, качество, цена, спрос.

Все должно быть сделано настолько просто, насколько это возможно, но не более.

А. Энштейн

Длительное время и до сих пор ведутся острейшие споры о значении классических экономических теорий - трудовой теории стоимости и теории предельной полезности. Каждая их названных теорий представляется авторами и последователями в качестве единственной основы всей системы рыночных отношений, а именно, теории стоимости.

Источником трудовой теории стоимости является труд.

Сторонники теории предельной полезности ищут такое единое основание в предельной полезности.

По отношению к этим теориям экономисты делятся на сторонников (последователей) трудовой теории стоимости и сторонников (последователей) теории предельной полезности. Имеется немало публикаций, в которых авторы, отмечая определенные недостатки в текущих трактовках трудовой теории стоимости и теории предельной полезности, пытаются примирить их сторонников. Даже известны попытки представить эти теории как исторические этапы формирования теории стоимости - от трудовой теории стоимости к теории предельной полезности.

Вопросы совместного влияния на рыночные отношения этих теорий стали предметом рассмотрения сторонниками неоклассического направления.

Новое направление (неоклассическое) в теории стоимости и цен разработано английским экономистом Альфредом Маршаллом (18421924).

По его мнению, обе теории страдают определенной односторонностью, поскольку объясняют стоимость только одним фактором.

Он высказался о необходимости синтеза предельной полезности и издержек производства при определении того, чем определяется стоимость товара.

«Мы могли бы с равным основанием спорить о том, регулируется ли стоимость полезностью или издержками производства, как и о том, разрезает ли кусок бумаги верхнее или нижнее лезвие ножниц. Действительно, когда одно лезвие удерживается в неподвижном состоянии, а резание осуществляется движением другого лезвия, мы можем, как следует не подумав, утверждать, что резание производит второе, однако такое утверждение не является совершенно точным, и оправдать его можно лишь претензией на простую популярность, а не строго научным описанием совершаемого процесса» (1).

С работами А. Маршалла связан отход от попыток построить монистическую теорию стоимости и цены. Принцип монизма означает, что должен быть найден единый источник стоимости, единое основание цены в рыночном хозяйстве.

Таким единственным источником, например, в трудовой теории стоимости является труд.

Теоретики австрийской школы ищут такое единое основание в предельной полезности. 
В теории же А. Маршалла определение стоимости и цены сводится к выяснению взаимодействия рыночных сил, лежащих как на стороне спроса (предельная полезность), так и предложения (издержки производства товара).

Но поскольку и спрос, и предложение сами зависят от сотен факторов, то и взаимодействие рыночных сил, лежащих на стороне спроса и предложения, не обладает определенностью. Неоклассическое направление не дает возможности оценить (измерить) это взаимодействие. Однако важным здесь является мысль о синтезе двух классических теорий - трудовой теории стоимости и теории предельной полезности.

Место понятия «Ценность» в системе экономических понятий определяется связью понятия «Ценность», в той или иной форме, с базовыми экономическими понятиями - потребностью и ресурсами.

Ценность блага должна отражать его способность удовлетворять потребности при соответствующих затратах ресурсов. Ценность блага будет возрастать при максимизации способности удовлетворять потребности и при минимизации затрат ресурсов.

Предметная характеристика блага - это его свойство быть полезным для потребителя, это его потребительская оценка. Здесь блага сравниваются между собой по полезности - способности удовлетворять потребности покупателя.

Сущность предметной характеристики блага - полезность, способность удовлетворять потребности. Форма выражения предметной характеристики блага - качество. Предметная характеристика блага составляет основу теории полезности, преобразованную в последующем в теорию предельной полезности.

Субъектная характеристика блага это выражение характеристики блага со стороны субъекта, определяемая не свойствами блага самими по себе, а их вовлеченностью в сферу человеческих интересов, возможностью реализации способности удовлетворять потребности как отдельного человека, так и человеческих сообществ.

Здесь блага сравниваются между собой по реальной возможности поступления блага в потребление покупателя, которое, при прочих равных условиях, зависит от затрат ресурсов на производства блага. Сущность этой характеристики блага - его стоимость. Форма выражения субъектной характеристики блага - цена.

Субъектная характеристика блага составляет основу теории стоимости, в развитом состоянии - трудовую теорию стоимости.

Ценность блага будет возрастать при возрастании предметной характеристики и снижаться возрастании его субъектной характеристики.

На сущностном уровне взаимосвязь характеристик ценности может выражаться следующей моделью:

Ценность = Полезность $/$ Стоимость .

На поверхности реальных экономических отношений взаимосвязь характеристик ценности может выражаться соотношением их форм:

Спрос $=$ Качество $/$ Цена.

Длительное время (около полутора столетия)

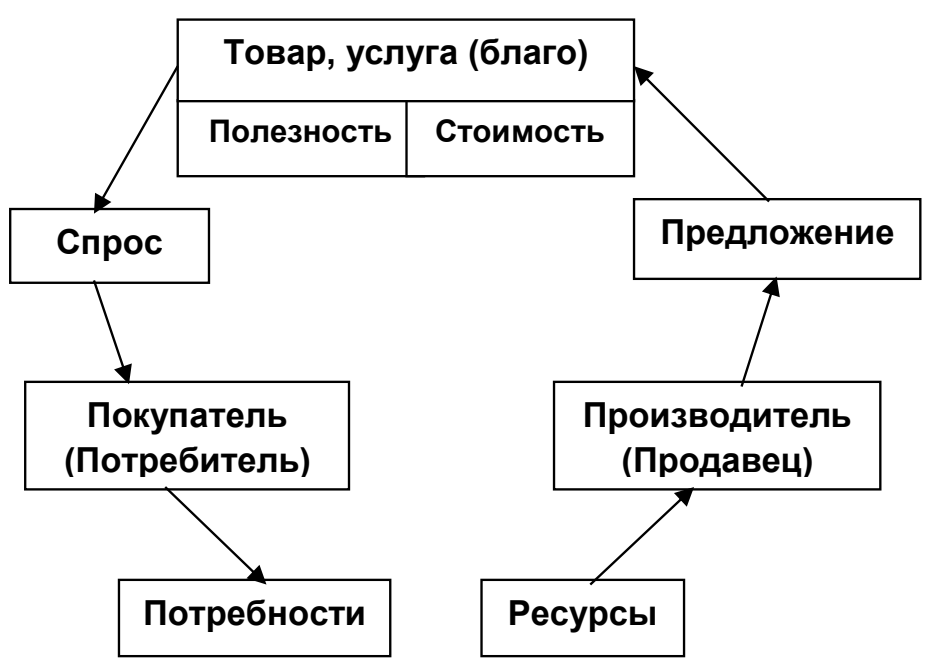

Рuc. 1. Иллюстрация решения главной задачи экономики максимизации удовлетворения потребностей имеющимися ресурсами 
Модели взаимосвязи сущностных понятий полезности, стоимости, ценности и форм их проявления в экономке

\begin{tabular}{|c|c|c|c|}
\hline $\begin{array}{l}\text { Форма } \\
\text { проявления }\end{array}$ & Цена & Качество & Спрос \\
\hline Сущность & Стоимость & Полезность & Ценность \\
\hline $\begin{array}{l}\text { Теория, отража- } \\
\text { ющая сущность }\end{array}$ & Трудовая теория стоимости & $\begin{array}{l}\text { Теория предельной } \\
\text { полезности }\end{array}$ & $\begin{array}{l}\text { Экономическая теория } \\
\text { ценности }\end{array}$ \\
\hline Научные школы & $\begin{array}{l}\text { Варианты трудовой теории } \\
\text { стоимости выдвигали осно- } \\
\text { ватели классической поли- } \\
\text { тической экономии: Уильям } \\
\text { Петти, Адам Смит, Давид Ри- } \\
\text { кардо. Завершённую форму } \\
\text { эта теория получила в трудах } \\
\text { Карла Маркса и поэтому она } \\
\text { обычно ассоциируется имен- } \\
\text { но с марксизмом. }\end{array}$ & $\begin{array}{l}\text { Теория предельной полезно- } \\
\text { сти - концепция в экономи- } \\
\text { ческой теории, возникшая в } \\
\text { пос-ледней трети ХІХ века. } \\
\text { Разрабатывалась представи- } \\
\text { телями австрийской школы: } \\
\text { К. Менгером, Э. Бём-Бавер- } \\
\text { ком, Ф. Визером, Й. Шумпе- } \\
\text { те-ром, а также Л. Вальрасом } \\
\text { (Лозанская школа), У.С. Дже- } \\
\text { вонсом и А. Маршаллом. }\end{array}$ & $\begin{array}{l}\text { Научная школа московских } \\
\text { вузов. } \\
\text { Публикации: } \\
\text { Стерликов Ф. Ф. Методоло- } \\
\text { гические вопросы анализа } \\
\text { трактовок о связи качества и } \\
\text { стоимости товара. М., ИНИ- } \\
\text { ОН АН СССР, 1984. } \\
\text { Гуськова М.Ф., Стер- } \\
\text { ликов П. Ф., Стерли- } \\
\text { ков Ф.Ф. Ценность, по- } \\
\text { лезность и стоимость } \\
\text { образовательных услуг. М., } \\
\text { «Экономические науки», } \\
\text { 2003. } \\
\text { Стерликов Ф. Ф., Стерликов } \\
\text { П.Ф., Гуськова M. Ф. Эконо- } \\
\text { мическая теория ценности. } \\
\text { Экономические науки. 2006, } \\
\text { № 6. } \\
\text { Sterlikov F.F., Sterlikov P.F., } \\
\text { Guskova M.F. About the } \\
\text { synthesis of economic } \\
\text { theories of cost and utility. } \\
\text { Monografiya. Warszava: DК- } \\
\text { DRUк, 2007. }\end{array}$ \\
\hline
\end{tabular}

ведутся ожесточенные споры о роли трудовой теории стоимости и теории предельной полезности в рыночных отношениях.

Одна плеяда ученых доказывала доминирующее значение трудовой теории стоимости, другая - теории предельной полезности.

Более того, историческую последовательность разработки этих теорий некоторые авторы пытались и сейчас пытаются представить как развитие теории стоимости - от трудовой теории стоимости к теории предельной полезности.

Отвлекаясь от идеологических причин, можно заметить, что преувеличение то одной, то другой теории связано с методологическими причинами, а именно: с рассмотрением экономических закономерностей только на двух уровнях хозяйствования: либо на микроэкономическом, либо на макроэкономическом уровне.

Деление хозяйствования на эти две большие части не обеспечивает всесторонности рассмотрения экономических закономерностей и вызывает неоправданное противостояние рассматриваемых теорий - трудовой теории стоимости и теории предельной полезности.
Наши исследования показали, что значение трудовой теории стоимости и теории предельной полезности можно выявить, если вести анализ рыночных взаимосвязей с пяти позиций (пяти уровней хозяйствования):

- экономики человека,

- экономики семьи,

- экономики предприятия,

- национальной экономики,

- мировой экономики.

На каждом уровне хозяйствования по-разному проявляется доминирование потребности и стоимости товара. Поэтому доминирование полезности и стоимости необходимо подвергнуть пятизвенному анализу.

Роль составляющих ценности на разных уровнях хозяйствования в обобщенном виде представлена на рисунке 2 .

На разных уровнях хозяйствования по-разному проявляют себя составляющие ценности, а именно полезности и стоимости.

Начнем анализ с самого низкого уровня хозяйствования - с экономики человека. На уровне экономики человека из двух составляющих 


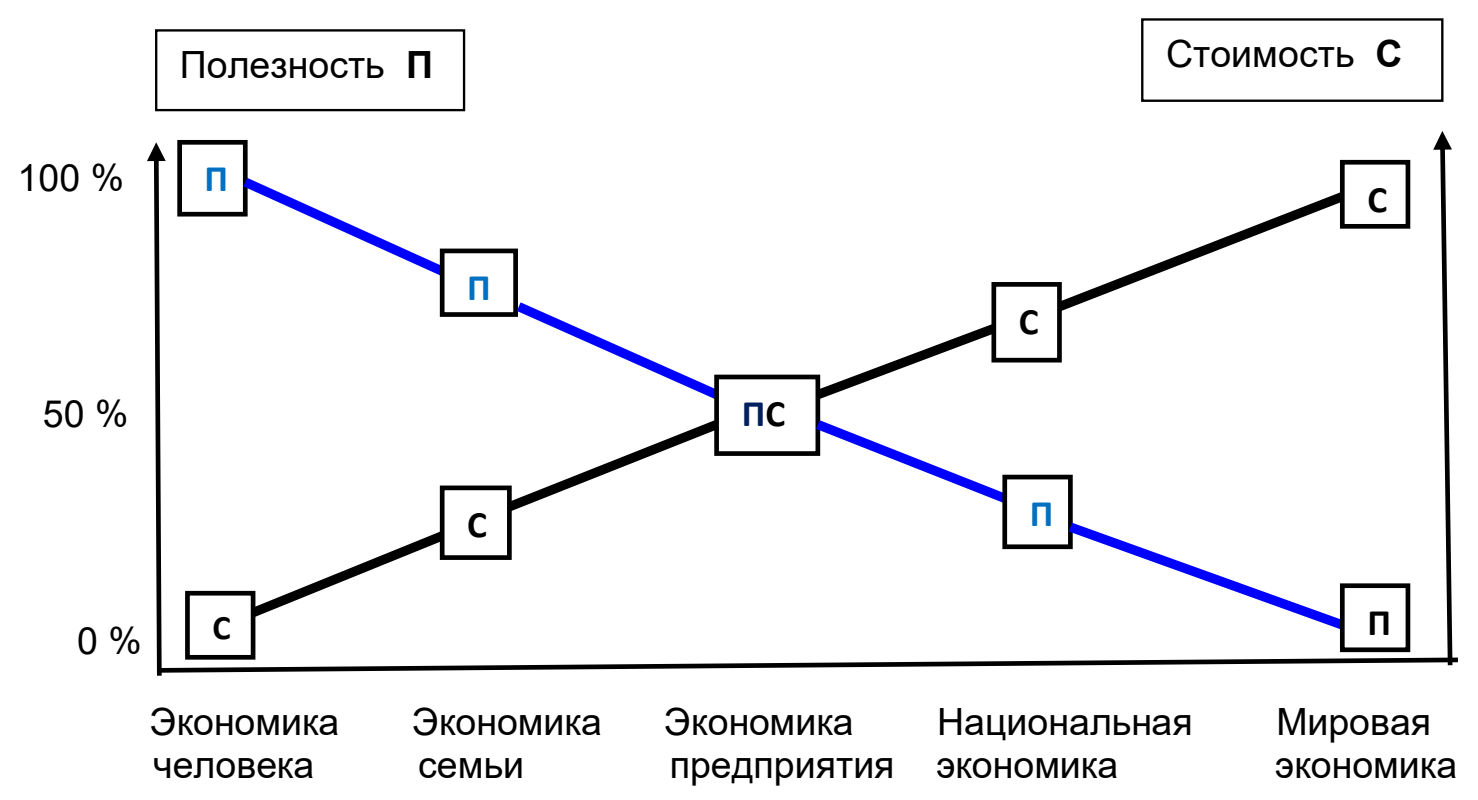

Рис 2. Схема, иллюстрирующая соотношение роли полезности и стоимости блага на разных уровнях хозяйствования (вверх - больше, вниз - меньше).

теории ценности в полной мере проявляет себя полезность.

Единица блага может иметь в пределе 7 млрд. уровней полезности (предельных полезностей по количеству жителей планеты).

Можно согласиться с применимостью в полной мере (100\%) на этом уровне теории предельной полезности. Она играет здесь решающую роль.

Стоимость на этом уровне проявляется в «сжатом», усредненном состоянии. Ее составляют средние общественные затраты абстрактного труда.

Стоимость блага на этом уровне в виде его цены является постоянной величиной, не зависимой от отдельного потребителя.

Если же исследовать хозяйствование на уровне мировой экономики, то можно убедиться, что полезность блага здесь не имеет вариативности. Полезность на этом уровне проявляется в «сжатом», усредненном состоянии.

Теория предельной полезности практически не участвует на уровне мировой экономики.

Рассмотрим ситуацию с производством яблок. Например, в мире производится 1 млн. т яблок. Дополнительное яблоко обладает не меньшей полезностью, чем предыдущее яблоко. Полезность яблока равна единице, как и всех предыдущих экземпляров.

На уровне мировой экономики в полной мере (100\%) проявляет себя только стоимость блага.

Единица блага может иметь множество форм выражения стоимости, а именно цен, на разных рынках: национальных, региональных и других. На уровне мирового хозяйствования в полной мере действует трудовая теория стоимости, играющая решающую роль.

Об этом неоднократно заявляли даже самые ярые противники трудовой теории стоимости.

Что касается других уровней хозяйствования, то можно отметить различное соотношение роли полезности и стоимости.

На уровне экономики отдельного предприятия значение полезности и стоимости блага примерно одинаковое. Не случайно именно микроэкономический анализ позволял исследователям находить аргументы (влияние, роль, значение) в рыночной экономике и в пользу трудовой теории стоимости, и в пользу теории предельной полезности.

Как показывает исторический анализ названных экономических теорий, скорее идеологические и политические аргументы оказывали влияние (давление) на более чем столетнее противостояние этих экономических теорий.

В современной экономической практике нашей страны данное соотношение полезности и стоимости учитывается. В качестве примера можно привести требования в Федеральном законе от 21 июля 2005 г. № 94-Ф3 «О размещении заказов на поставки товаров, выполнение работ, 
оказание услуг для государственных и муниципальных нужд».

«Статья 28. Оценка и сопоставление заявок на участие в конкурсе.

Пункт 4. Для определения лучших условий исполнения контракта, предложенных в заявках на участие в конкурсе, конкурсная комиссия должна оценивать и сопоставлять такие заявки... в соответствии со следующими критериями:

1) функциональные характеристики (потребительские свойства) или качественные характеристики товара, качество работ, услуг;

2) расходы на эксплуатацию товара...

7) цена контракта...».

Можно привести и еще один пример (хотя и негативной практики).

Несколько лет назад в одном из районов
Москвы грант на поставку детского питания в детский сад выиграла фирма исключительно по показателю низкой стоимости. Но через два месяца от поставщика пришлось отказаться, поскольку дети «почему-то» отказывались от еды и родители возмутились. Фирма проигнорировала специфическое качество (форму полезности) детского питания.

Таким образом, можно констатировать, что какие бы предпочтения теориям стоимости и полезности ни отдавались учеными, экономическая практика вынуждена учитывать и полезностную, и стоимостную характеристики товара.

Спрос на товар определяют и его качество, и цена. А это подтверждает объективность проявления и использования теории ценности товара.

\section{Библиографический список}

1. Маршал Альфред. Принципы экономической науки. Москва. 1993, С. 175.

2. Гуськова М.Ф.. Матвеев М.Ю. и др. К вопросу показателей качества строительства как составляющей ценности // Вопросы экономики и права, 2015, № 1, с. 86-89.

3. Гуськова М.Ф.. Карданская Н.Л. и др. Экономические потребности на разных уровнях хозяйствования // Вопросы экономики и права. 2013. № 9, с. 60-65.

4. Гуськова М.Ф., Стерликов П.Ф., Стерликов Ф.Ф. Ценность, полезность и стоимость образовательных услуг: монография Москва. 2003.

5. Стерликов Ф.П. К вопросу о собственности как юридической и экономической категории // Вопросы экономики и права. 2017. № 2, с. 12-15.

6. Стерликов Ф.Ф., Стерликов П.Ф., Гуськова М.Ф. Экономическая теория ценности. Экономические науки. 2006. № 6.

7. Стерликов Ф.Ф. Методологические вопросы анализа трактовок о связи качества и стоимости товара. Москва. 1984.

8. Sterlikov F. F., Sterlikov P.F., Guskova M.F. About the synthesis of economic theories of cost and utility. Monografiya. Warszava: DK-DRUK, 2007. 